Review Article

\title{
A Bibliometric Analysis and Visualization of Fractional Order Research in China over Two Decades (2001-2020)
}

\author{
Yunfei Yang $\mathbb{D}$, Ke Lv $\mathbb{D}$, Jian Xue $\mathbb{D}$, and Xi Huang $(\mathbb{D}$ \\ School of Engineering Science, University of Chinese Academy of Sciences, Beijing 100049, China \\ Correspondence should be addressed to Jian Xue; xuejian@ucas.ac.cn
}

Received 15 June 2021; Accepted 28 July 2021; Published 13 August 2021

Academic Editor: Lifeng Wu

Copyright ( $\odot 2021$ Yunfei Yang et al. This is an open access article distributed under the Creative Commons Attribution License, which permits unrestricted use, distribution, and reproduction in any medium, provided the original work is properly cited.

\begin{abstract}
Fractional order research has interdisciplinary characteristics and has been widely used in the field of natural sciences. Therefore, fractional order research has become an important area of concern for scholars. This paper used 2854 literatures collected from China National Knowledge Infrastructure (CNKI) database from 2001 to 2020 as the data source and used bibliometrics and two visualization methods to conduct bibliometric analysis and visualization research on China's fractional order research. To begin with, this paper analyzed the time series distribution of publications, the distribution of research institutions, the author cooccurrence network, the distribution of important journals, and the distribution of important literature, which explained the research status of the fractional order. Furthermore, this paper used VOSviewer software to analyze the clustering and density distribution of the fractional order research keywords, which revealed the hotspots of the fractional order research. Finally, with the help of CiteSpace software, the burst keywords were analyzed to further explore the frontiers of fractional order research. This paper systematically reveals the research status, research hotspots, and research frontiers of China's fractional order research, which can provide certain theoretical and practical references for related follow-up researchers.
\end{abstract}

\section{Introduction}

The fractional calculus is a name for the theory of integrals and derivatives of arbitrary order, which unifies and generalizes the notions of integer-order differential and integral [1]. The idea of fractional calculus is known in developing regular calculation referring to Leibniz and L'hospital's work in 1695 [2]. Fractional calculus was introduced more than 300 years ago [3], and it was introduced by Leibniz in the scope of mathematics by the end of the 17th century [4]. The research on fractional calculus experienced its boom in the past decades [5], and recently this mathematical tool has found its way in various branches of science and engineering [6], such as electrical and electronic engineering [7, 8], automation control systems $[9,10]$, and computer science information systems $[11,12]$. Therefore, the related research of fractional order has attracted the wide attention of international scholars.

In recent years, scholars have conducted reviews around the relevant topics of fractional order research and have achieved relatively rich research results, such as literatures [2-6]. In addition, other scholars focused on specific areas of fractional order research and reviewed them, such as the research field of fractional order control [13-15] and the research field of image processing $[16,17]$. There is no doubt that the research results of the above scholars have contributed to the advancement of fractional order research and can also provide reference and support for subsequent scholars to further deepen the relevant research of fractional order. However, it is difficult to comprehensively extract the common elements and core points of the literature to a certain extent if the comprehensive analysis of the long term and a large amount of literature is conducted by combination, summary, and other methods. Furthermore, in this case, the researchers may find it difficult to avoid the subjective influence in the analysis process, so its scientificity is worth discussing.

Bibliometrics and visualization software are effective tools for analyzing mass literature [18]. VOSviewer is a software tool for constructing and visualizing bibliometric 
networks [19], which can be used to construct maps of authors or journals based on cocitation data or to construct maps of keywords based on cooccurrence data [20]. Meanwhile, VOSviewer has an advanced graphic presentation capability that is suitable for large-scale data and locates key points and hotspots in scientific research using density view [21]. In addition, CiteSpace is a knowledge visualization tool developed by Dr. Chen Chaomei [22], which combines citation analysis and cocitation analysis to transform literature data from abstract data into visual and intuitive maps of scientific knowledge through information visualization, helping researchers find research hotspots, and frontiers in a scientific field [23].

In summary, regarding the related research of fractional literature review, many scholars reviewed the related research of fractional order from a micro perspective, that is, focusing on a specific area of the fractional order for exploration. However, there are few related research results of literature analysis on the overall fractional research from a macro perspective. At the same time, from the perspective of literature analysis methods, many scholars used methods such as combination and induction, but, with the help of visual analysis software, the findings of visual research on fractional research are rarely found.

Therefore, this paper collected the research data of China's fractional literature from 2001 to 2020 and used bibliometrics and two visualization research methods to analyze the literature of China's fractional order over two decades. The purpose of this paper is to analyze the research status and explore the hotspots and research frontiers of China's fractional order research. To be specific, this paper used the method of bibliometric analysis to explore the time series distribution of publications, the distribution of research institutions, the author cooccurrence network, the distribution of key journals, and the distribution of important literature, which clarified the research status of fractional order. Furthermore, it used VOSviewer to analyze the clustering and density distribution of the fractional research keyword network and used CiteSpace to analyze the fractional research burst keywords, which can reveal the hotspots and research frontiers of the fractional order research. This paper systematically analyzes and explores the research status, research hotspots, and frontier fields of fractional order research, which enriches the content system of fractional order research to a certain extent and can also provide some references for scholars to explore and further deepen the research on fractional order.

\section{Research Methods and Data Sources}

The research methods of this paper mainly include bibliometric analysis and visualization research methods. Firstly, this paper used the bibliometric analysis method to analyze the publications, research institutions, important journals, and important literature of fractional order research, which can explore the current status of fractional order research. Secondly, VOSviewer and CiteSpace software were used to visualize the fractional order research. To be specific, VOSviewer was used to analyze the author cooccurrence network, keyword network, keyword density, and so forth of fractional order research, thus revealing the author cooperation situation and research hotspots of fractional order research. Meanwhile, CiteSpace was used to analyze the burst keywords of fractional order research, thereby further exploring the frontiers of fractional order research.

The data of this paper came from China National Knowledge Infrastructure (CNKI). The literature retrieval conditions were as follows: set the title as fractional order, selected the categories of the sources as SCI source journals, EI source journals, core journals, CSSCI, and CSSCD, selected the period time from 2001 to 2020, and a total of 2854 literatures were retrieved. In view of this, 2854 literatures were retrieved as research data sources, and the retrieval date was May 18, 2021. It should be noted that the bibliometric data of this paper are all from CNKI statistics.

\section{Research Status}

This study focused on the perspective of the time series distribution of publications, the distribution of research institutions, the author cooccurrence network, the distribution of important journals, and the distribution of important literature and used the bibliometric analysis method to explore the research status of fractional order.

3.1. Time Series Distribution of Publications. The dynamic change of the publications with time evolution can effectively reveal the degree of concern in a certain research field. Therefore, this paper made a quantitative analysis on the time series distribution of 2854 papers on fractional order research in the CNKI database. The results are shown in Figure 1.

It can be seen from Figure 1 that the publications of fractional order research show an overall upward trend during the research period (2001-2020), but there are obvious differences in the distribution of publications in different time series phases. To be specific, the time series distribution of the publications of fractional order research can be divided into the four following phases: The first phase is from 2001 to 2010; the total number of publications in this phase is relatively small, accounting for about $15 \%$ of the total number of publications in the past 10 years, especially from 2001 to 2006, and the average annual number of publications in fractional order research is less than 20, so the first phase belongs to the slow development phase of fractional order research. The second phase is from 2010 to 2014; this phase belongs to the rapid growth phase of fractional order research. During this period, the publications of fractional order research continued to emerge, which indicates that Chinese scholars pay more and more attention to fractional order research. Especially in 2011, the number of publications in fractional order research increased by $68.13 \%$ compared with the previous year, and the number of publications in that year exceeded 100 for the first time. Therefore, it can be considered that 2011 is the transition period of fractional order research. The third phase is from 2014 to 2019; the average number of annual 


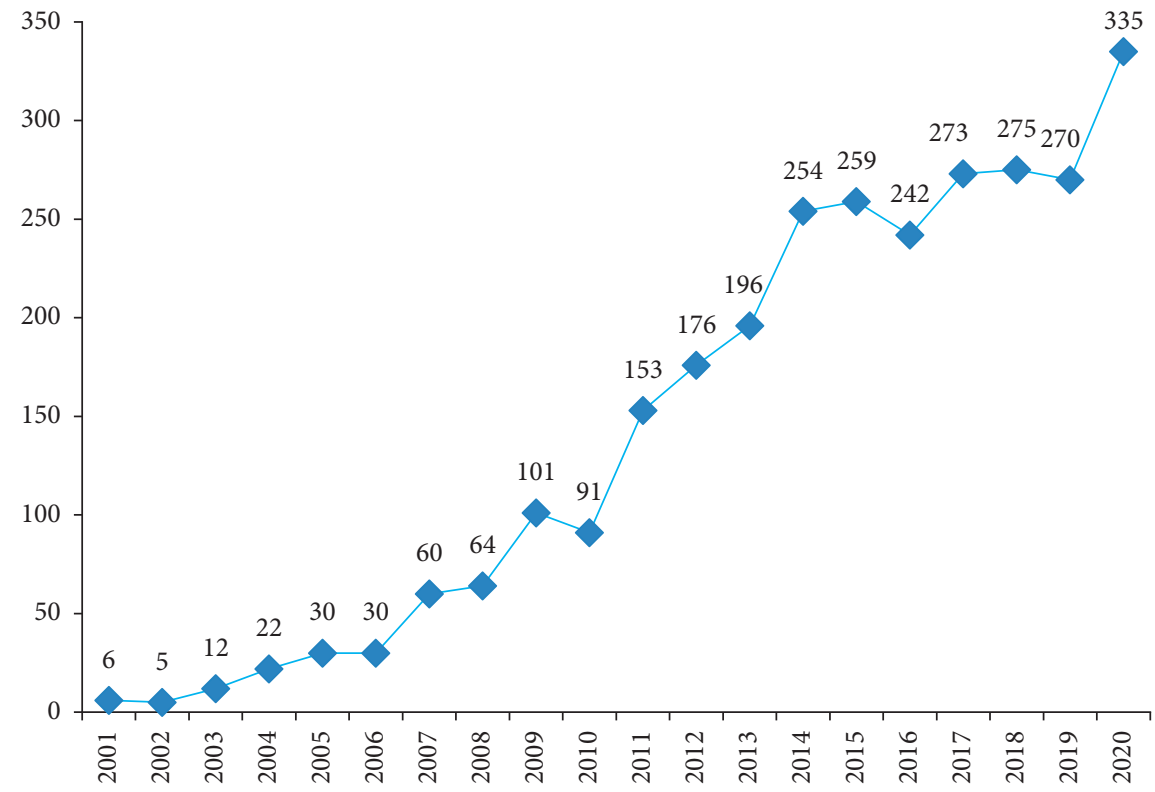

FIgURE 1: Time series distribution of publications.

publications in this phase is about 260, and there is a little difference in the number of publications each year, which indicates that the fractional order research has entered a phase of steady development. The fourth phase is from 2019 to 2020; the publications of fractional order research continued to grow, and the publications exceeded 300 for the first time in 2020. This phase belongs to the sustained growth phase of fractional order research, which shows that Chinese scholars' attention to fractional order research continues to advance.

3.2. Distribution of Research Institutions. In order to further explore the distribution of the main research power of fractional order, this paper made a quantitative analysis of the top 25 research institutions in the publications of fractional order research. The results are shown in Figure 2.

Figure 2 shows the distribution of the publications by the main research institutions. These research institutions are an important power of fractional order research and play an important role in promoting the development of fractional order research. Among them, Sichuan University has the largest number of publications on fractional order research, up to 95. Anhui University, Beijing Institute of Technology, Zhengzhou University of Aeronautics, and Yanshan University also published more papers; all of them have published more than 50 papers, which are $71,66,62$, and 53, respectively. Therefore, it can be considered that these research institutions have an important influence on the development of fractional order research in China. In addition, according to the horizontal comparison of the publications by research institutions in Figure 2, we can see that the overall difference in the number of publications by research institutions is relatively small. Combined with data statistics, it can be seen that the average number of publications by the main research institutions in Figure 2 is about 45, which indicates that the distribution of fractional order research publications among research institutions is relatively balanced. Additionally, further analysis of the attributes of research institutions shows that the distribution of fractional order research institutions includes comprehensive universities, science, engineering universities, and military academy. In summary, the bibliometric analysis of the distribution of main research institutions in the fractional order can contribute to understanding the publications and attributes of research institutions for scholars.

3.3. Author Cooccurrence Network. This paper used VOSviewer to analyze the author cooccurrence network of fractional order research. The parameter options were set as follows: chose coauthorship for type of analysis, authors for unit of analysis, full counting for counting method, and 3 for the minimum number of documents of an author, thereby generating the author cooccurrence network visualization map, as shown in Figure 3.

Figure 3 shows the author cooccurrence network of fractional order research, in which the node size is related to the publications by authors, and the larger the node, the more publications by authors. The thickness of connecting lines and distance between nodes is significantly related to the cooperative relationship between authors. The thicker the connection and the closer the location between nodes, the closer the cooperation relationship between authors.

As can be seen from Figure 3, based on the global perspective analysis, it can be found that the author cooccurrence network nodes of fractional order research are relatively scattered, the overall connecting lines between nodes are relatively few, and the network distribution and connecting lines between nodes do not show obvious network cooperation relationship. Therefore, it can be considered that the overall cooperation intensity among authors 


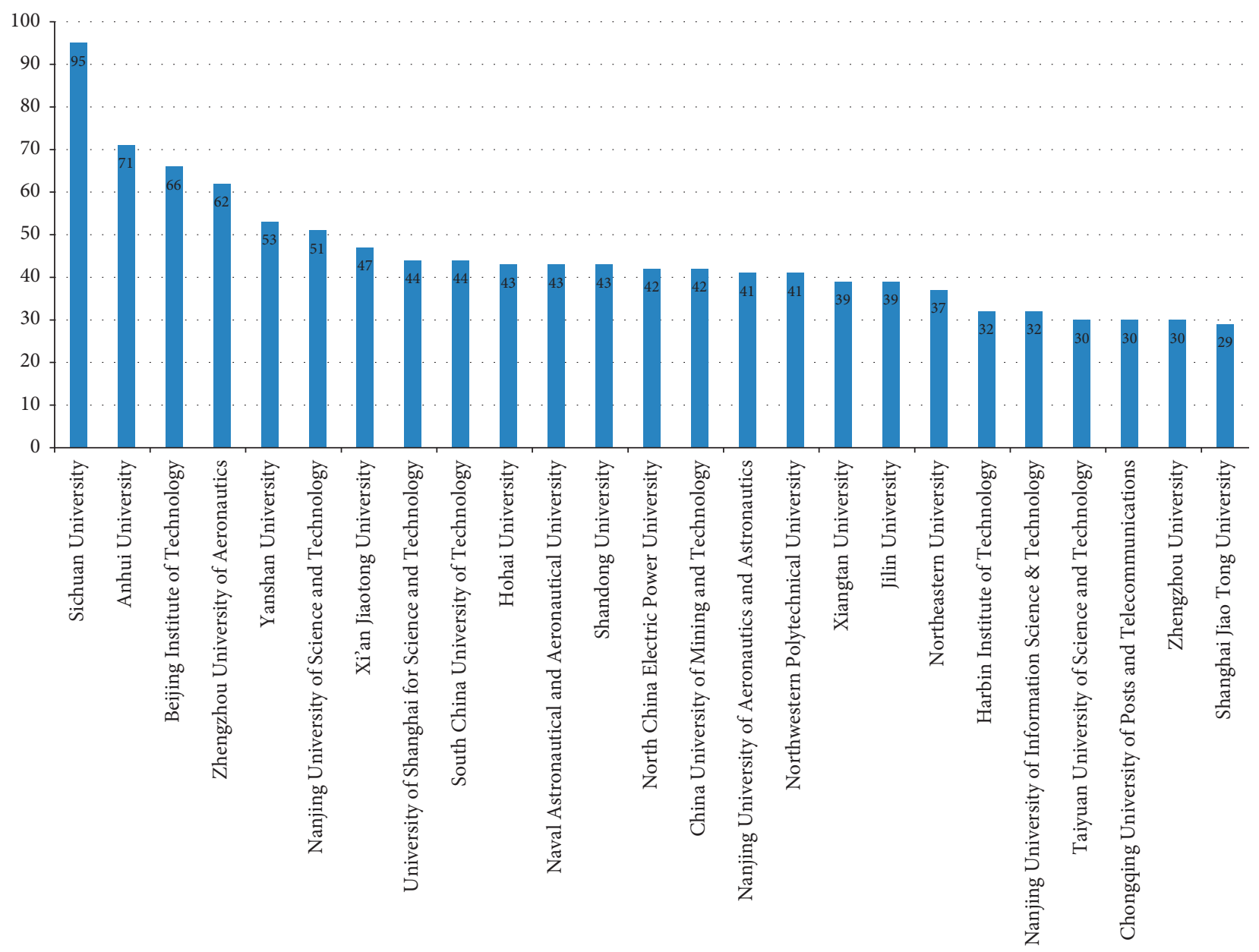

FIGURE 2: Distribution of main research institutions.

in fractional order is not high. However, based on the local perspective analysis, it can be found that some of the nodes are large and show a relatively close cooperative relationship, such as scholars Mao Beixing, Jiang Wei, Tao Ran, Pu Yifei, and $\mathrm{Hu}$ Weimin. These authors are in a relatively central position in the cooccurrence network and form a strong cooperative relationship with other scholars in the research group. Therefore, the global and local perspective analysis shows that the overall cooperation intensity of fractional order research is not high, but there are many research groups with a big number of publications and strong cooperation relationships.

3.4. Distribution of Important Journals. To a certain extent, the publications in a journal can reflect its influence in a certain research field. Statistics on the number of publications in a journal in fractional order research are also of great significance for revealing the distribution of fractional order research disciplines. In view of this, this paper made a quantitative analysis of the top 15 journals in terms of the publications of fractional order research. The results are shown in Table 1.

As can be seen from Table 1, regarding fractional research, Acta Physica Sinica has the largest number of publications, with 123 papers. Meanwhile, Mathematics in Practice and Theory, Journal of Jilin University (Science Edition), Mathematica Applicata, and Journal of Shandong University (Natural Science) also have more publications, which show that these journals have an important influence in the field of fractional order research. From the number of publications and subject areas of journals, we can see that publications in mathematics are the largest, such as Mathematics in Practice and Theory and Mathematica Applicata. At same the time, some other journals also involve the research publications of mathematics, such as Applied Mathematics and Mechanics and Acta Mathematica Scientia. In addition, the publications of fractional order research are also involved in physics, computer, control engineering, and other fields, such as Acta Physica Sinica, Computer Engineering and Applications, and Control Engineering of China. Therefore, it indicates the interdisciplinary attribute of fractional order research.

3.5. Distribution of Important Literature. To further explore the highly cited literature of fractional order research, this paper made a bibliometric analysis on the top 10 cited literatures of fractional order research. The results are shown in Table 2. 


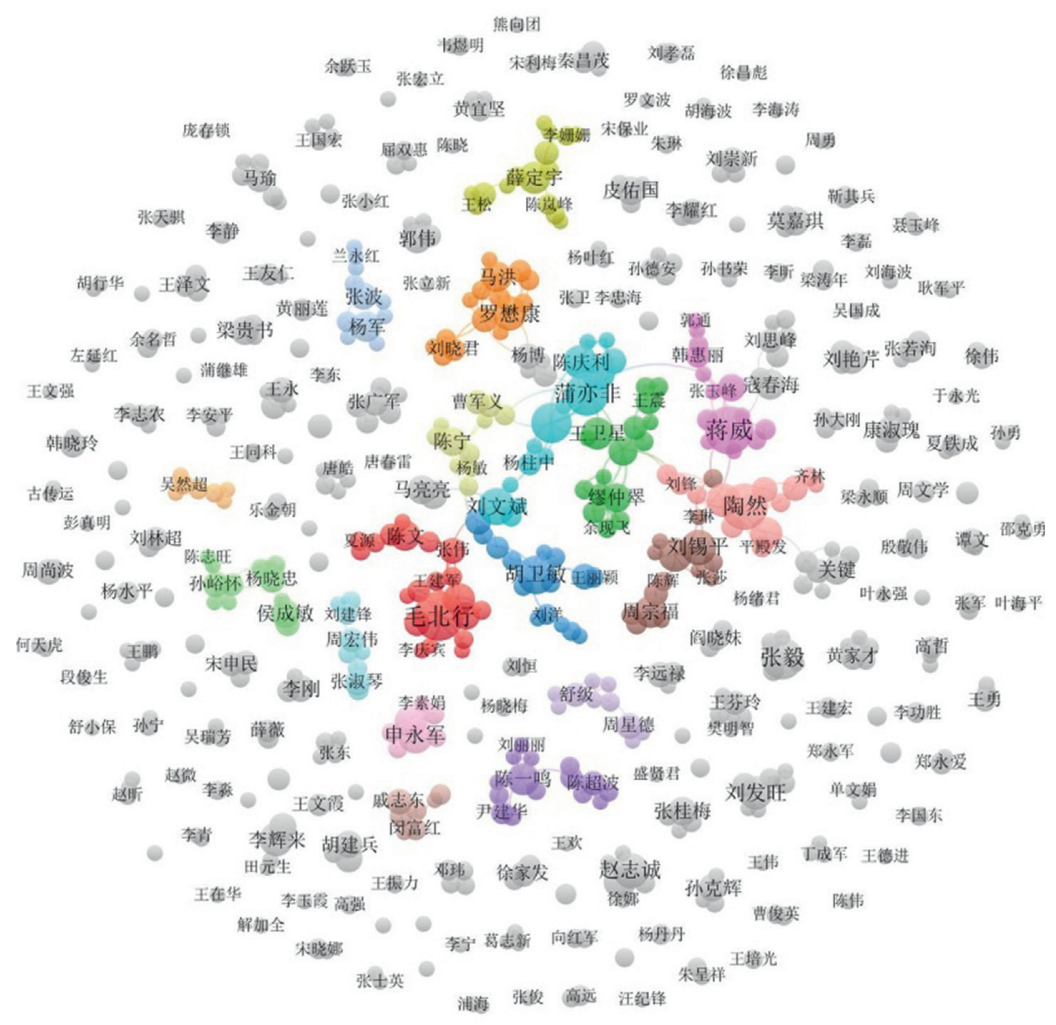

9. VOSviewer

Figure 3: Author cooccurrence network. Note: due to the large number of authors in Figure 3 and limited space, this paper only translates the names of the following authors: 毛北行 = Mao Beixing; 蒋威 = Jiang Wei; 陶然 = Tao Ran; 蒲亦菲 = Pu Yifei; and 胡卫敏 = Hu Weimin.

TABLE 1: Statistics of the top 15 journals publications.

\begin{tabular}{lcc}
\hline No. & Journal title & Publications \\
\hline 1 & Acta Physica Sinica & 123 \\
2 & Mathematics in Practice and Theory & 119 \\
3 & Journal of Jilin University (Science Edition) & 76 \\
4 & Mathematica Applicata & 53 \\
5 & Journal of Shandong University (Natural Science) & 50 \\
6 & Journal of Sichuan University (Natural Science Edition) \\
7 & Computer Engineering and Applications \\
8 & Control Engineering of China \\
9 & Applied Mathematics and Mechanics \\
10 & Acta Electronica Sinica \\
11 & Acta Mathematica Scientia \\
12 & Control Theory \& Applications \\
13 & Journal of Electronics \& Information Technology \\
14 & Science Technology and Engineering \\
15 & Application Research of Computers \\
\hline
\end{tabular}

It can be seen from Table 2 that Detection and parameter estimation of multi-component LFM signals based on fractional Fourier transform is the most frequently cited literature in the fractional order research, and this paper proposed a method of multicomponent LFM signal detection and parameter estimation based on fractional Fourier transform [24]. Meanwhile, the frequently cited literatures in Table 2 such as Dimensional normalization in the digital computation of the fractional Fourier transform and Research progress of fractional Fourier transform in the field of signal processing are also related to the fractional Fourier transform, so this also reflects the importance of the fractional Fourier transform in the field of fractional order research. Based on the perspective of literature attribute analysis, there are many review literatures about fractional order, such as Summary of research on fractional-order control, Research progress of fractional Fourier transform in the field of signal processing, and Summary of research on image processing 
TABLE 2: Statistics of top 10 important literatures cited in frequency.

\begin{tabular}{|c|c|c|c|c|}
\hline No. & Literature & First author & $\begin{array}{l}\text { Citation } \\
\text { frequency }\end{array}$ & Year \\
\hline 1 & $\begin{array}{c}\text { Detection and parameter estimation of multi-component LFM signals based on fractional } \\
\text { Fourier transform }\end{array}$ & Qi lin & 358 & 2003 \\
\hline 2 & Design of fractional PID controller for fractional order system & Xue Dingyu & 352 & 2007 \\
\hline 3 & Dimensional normalization in the digital computation of the fractional Fourier transform & Zhao Xinghao & 263 & 2005 \\
\hline 4 & Summary of research on fractional-order control & $\begin{array}{l}\text { Zhu } \\
\text { Chengxiang }\end{array}$ & 216 & 2009 \\
\hline 5 & Research progress of fractional Fourier transform in the field of signal processing & Tao Ran & 182 & 2006 \\
\hline 6 & Image enhancement based on fractional differentials & $\begin{array}{c}\text { Yang } \\
\text { Zhuzhong }\end{array}$ & 177 & 2008 \\
\hline 7 & Fractional order sliding-mode control for permanent magnet synchronous motor & Zhang Bitao & 134 & 2012 \\
\hline 8 & $\begin{array}{c}\text { Fractional differential masks of digital image and their numerical implementation } \\
\text { algorithms }\end{array}$ & Pu Yifei & 130 & 2007 \\
\hline 9 & Application of fractional differential approach to digital image processing & $\mathrm{Pu}$ Yifei & 121 & 2007 \\
\hline 10 & Summary of research on image processing using fractional calculus & Huang Guo & 117 & 2012 \\
\hline
\end{tabular}

using fractional calculus. In addition, it can be seen from the year of publication that most of the highly cited literatures of fractional order research were published before 2010, while the highly cited literatures after 2010 were relatively few; both groups of literatures provide important support for the development of fractional order research.

\section{Research Hotspots and Frontier Analysis}

This study used VOSviewer to analyze the cooccurrence of the keywords, combined with CiteSpace to analyze the burst keywords, thereby revealing the hotspots and research frontiers of the fractional research.

4.1. Research Hotspots. The keyword is the core and essence of a document, which is a high-level summary of the content of the article [25]. After cluster analysis and words frequency count, topics and research hotspots can be known [26]. In view of this, this paper visually analyzed the cooccurrence of keywords in fractional order research using VOSviewer, which can explore the distribution of hotspots in fractional order research. To be specific, it selected type of analysis as cooccurrence, unit of analysis as keywords, and full counting as counting method and set minimum number of occurrences of a keyword to 18. Moreover, the keywords were merged and cleaned; that is, the different expressions of fractional Fourier transform were merged, and the repeated English keywords were cleaned. On this basis, by adjusting the clustering option and running the software to generate the keyword network and density visualization view, as shown in Figure 4 and Figure 5, respectively, it should be noted that this paper also tried to merge the keywords of fractional PID controller and fractional order $\mathrm{PI}^{\lambda} \mathrm{D}^{\mu}$ controller as well as fractional order and fractional calculus with the same method as above, but it was not successful. However, because fractional PID controller and fractional order $\mathrm{PI}^{\lambda} \mathrm{D}^{\mu}$ controller are distributed in the same cluster, there is only a slight difference in expression. Meanwhile, the fact that fractional order and fractional calculus are not merged has almost no effect on the cluster distribution, and the clustering distribution formed by software operation is still clear. Thus, the fact that these keywords were not merged has almost no effect on the analysis results.

In order to further explore the distribution of highfrequency keywords in fractional order research, the occurrences of the top 20 keywords were counted, as shown in Table 4.

According to Table 4, the most frequent keyword of fractional order research is fractional order (342), which is consistent with the retrieval method of this study. Meanwhile, the core keywords of fractional order theory, such as fractional differential equation, fractional Fourier transform, and fractional calculus, have high frequencies of 250, 243, and 228, respectively, which shows that these keywords are the key to the subject of fractional order research. In addition, fixed point theorem, positive solution, stability, chaos synchronization, sliding mode control, image enhancement, and so forth have a relatively high frequency of occurrence and involve multiple disciplines. Therefore, it can be also shown that the research of fractional order presents the characteristic of diversification.

Figure 4 shows the distribution of hot keywords in fractional order research, and different colors in the figure represent different clusters of research hotspots. Figure 4 is mainly composed of nodes and connecting lines. The larger the keyword node, the higher the frequency of occurrence, and the thicker the line between nodes, the higher the cooccurrence frequency. Moreover, the distribution of the distance between nodes is positively correlated with the relevance of keywords.

According to Figure 4, the research hotspots of fractional order are divided into four keyword clusters, and the different clusters represent the distribution of fractional order research in different fields.

Cluster 1 (red region) represents the research of fractional order in the field of mathematics. Cluster 1 has 25 keywords, including fractional differential equation, fixed point theorem, positive solution, boundary value problem, stability, and existence, and it is the largest cluster in the distribution of research hotspots of fractional order. According to the distribution of nodes, the high-frequency 


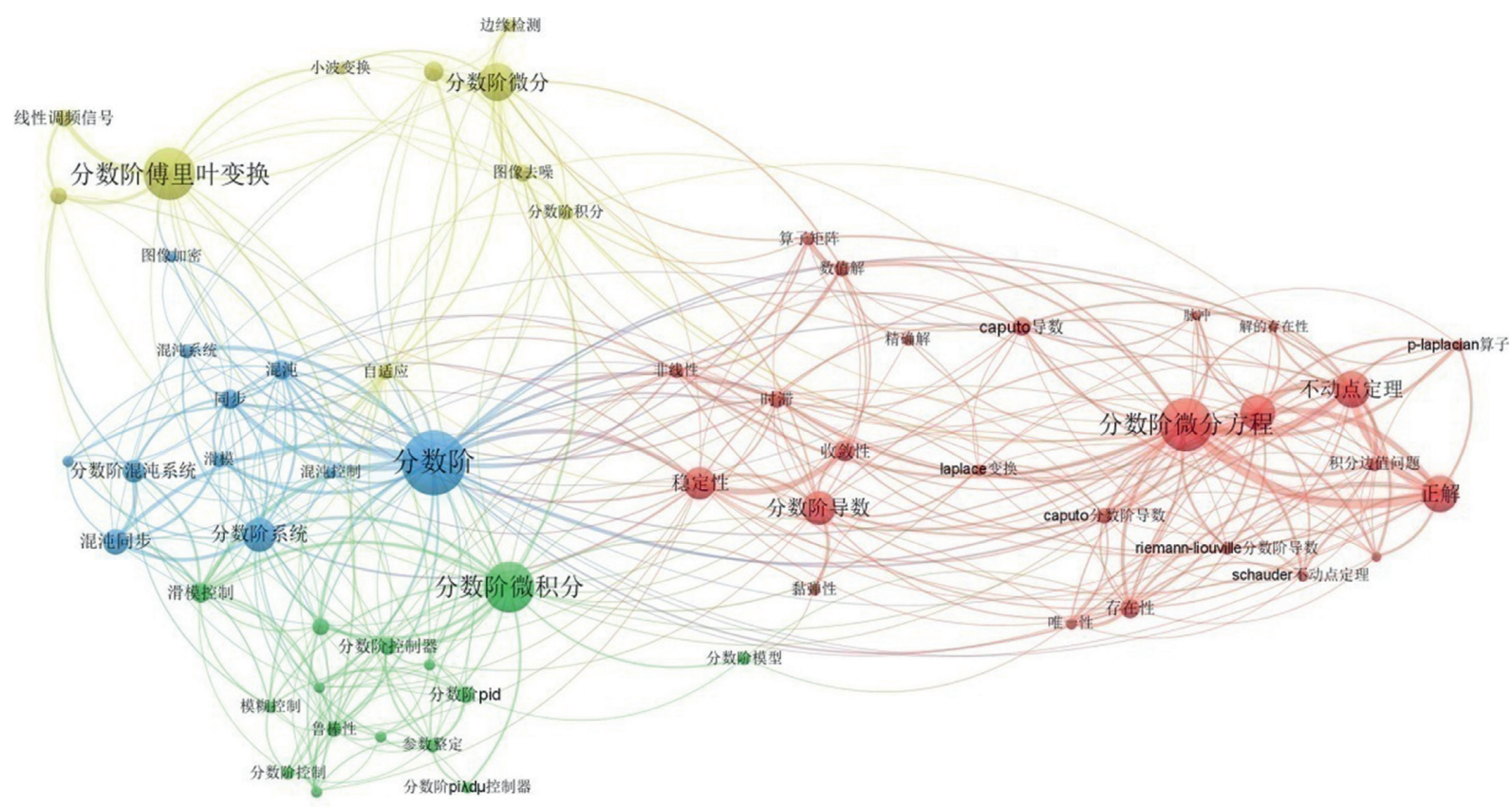

VOSviewer

Figure 4: Keyword network visualization map. Note: the keywords translation in Figure 4 is shown in Table 3.

keywords are relatively close and the connecting lines are relatively thick, such as fractional differential equation, boundary value problem, fixed point theorem, and positive solution. Scholars took this kind of keyword as the mainline to carry out related research, such as using fixed point theorem to explore the positive solutions of boundary value problems of fractional differential equations with different properties [27-29]. There were also some scholars who proved, respectively, the existence of positive solutions for the boundary value problem of a class of nonlinear fractional different equations [30] and a class of fractional differential equations on the infinite interval [31] based on the fixed point theorem. Meanwhile, also some keywords have relatively high occurrence frequencies, such as fractional derivatives, stability, and convergence, which also represent the research hotspots of fractional orders in the field of mathematics. Especially for stability and convergence, their nodes are closer and lines are thicker, which means that the cooccurrence degree between them is high. Some scholars proposed a difference scheme for solving the fractional diffusion equation, such as a difference scheme for threedimensional space fractional advection-diffusion equation [32] and a finite difference scheme for Riesz Space fractional diffusion equation [33]; the stability and convergence were proved by the matrix method. Furthermore, from the node distribution, it can be seen that the keywords in cluster 1 are scattered and compared with those in other clusters; this cluster involves the biggest number of keywords which indicates that the research of fractional order in the field of mathematics covers a wide range, and the research hotspots are relatively scattered.

Cluster 2 (green region) represents the research of fractional order in the field of control engineering. Cluster 2 has 15 keywords, including fractional calculus, sliding mode control, fractional order controller, fractional order PID, permanent magnet synchronous motor, sliding mode, and fractional order control. Compared with cluster 1, this cluster has a shorter distance between nodes, and the network connection is relatively close, which indicates that the research of fractional order in the field of control engineering is relatively concentrated. According to the distribution of keywords in cluster 2, the research hotspots of fractional order in the field of control engineering include the research of fractional order sliding mode control method and strategy and fractional order controller design, and so forth. Among them, regarding the research of fractional order sliding mode control method and strategy, some scholars put forward fractional order sliding mode control method and strategy based on the fractional order calculus theory and neural network, such as ANN-inversion system based fractional order sliding mode control scheme [34], fractional order sliding mode control scheme based on neural network and adaptive control algorithm [35], and fractional order sliding mode control algorithm based on radial basis function (RBF) neural network [36]. Regarding the research of fractional order controller design, it includes fractional order PID controller design [37-40], fractional order internal model controller design [41, 42], fractional order nonsingular terminal sliding mode controller [43], and fractional order PID improved autodisturbance rejection controller (FOPID-IADRC) [44]. In addition, the frequency of permanent magnet synchronous motor is relatively high, which is also one of the research hotspots in the field of fractional order control engineering. Zhou et al. studied the fractional order $\mathrm{PI}^{\lambda}$ controller parameters design method of permanent magnet synchronous generation wind 
Table 3: Translation of keywords in Figures 4 and 5.

\begin{tabular}{|c|c|c|}
\hline No. & The keywords & Translation \\
\hline 1 & Caputo分数阶导数 & Caputo fractional derivative \\
\hline 2 & Caputo导数 & Caputo derivative \\
\hline 3 & Green函数 & Green function \\
\hline 4 & Laplace变换 & Laplace transform \\
\hline 5 & $p$-laplacian算子 & $p$-Laplacian operator \\
\hline 6 & Riemann-Liouville分数阶 & Riemann-Liouville fractional order \\
\hline 7 & Schauder不动点定理 & Schauder fixed point theorem \\
\hline 8 & 不动点定理 & Fixed point theorem \\
\hline 9 & 分数阶导数 & Fractional derivative \\
\hline 10 & 分数阶微分方程 & Fractional differential equation \\
\hline 11 & 唯一性 & Uniqueness \\
\hline 12 & 存在性 & Existence \\
\hline 13 & 收敛性 & Convergence \\
\hline 14 & 数值解 & Numerical solution \\
\hline 15 & 时滞 & Time lag \\
\hline 16 & 正解 & Positive solution \\
\hline 17 & 积分边值问题 & Integral boundary value problem \\
\hline 18 & 稳定性 & Stability \\
\hline 19 & 算子矩阵 & Operator matrix \\
\hline 20 & 精确解 & Exact solution \\
\hline 21 & 脉冲 & Pulses per second \\
\hline 22 & 解的存在性 & The existence of solutions \\
\hline 23 & 边值问题 & Boundary value problem \\
\hline 24 & 非线性 & Nonlinear \\
\hline 25 & 愁弹性 & Viscoelasticity \\
\hline 26 & 内模控制 & Internal model control \\
\hline 27 & 分数阶pid & Fractional order PID \\
\hline 28 & 分数阶pid控制器 & Fractional order PID controller \\
\hline 29 & 分数阶PI ${ }^{\lambda} \mathrm{D}^{\mu}$ 控制器 & Fractional order $\mathrm{PI}^{\lambda} \mathrm{D}^{\mu}$ controller \\
\hline 30 & 分数阶微积分 & Fractional calculus \\
\hline 31 & 分数阶控制 & Fractional order control \\
\hline 32 & 分数阶控制器 & Fractional order controller \\
\hline 33 & 分数阶模型 & Fractional order model \\
\hline 34 & 参数整定 & Parameter tuning \\
\hline 35 & 模糊控制 & Fuzzy control \\
\hline 36 & 永磁同步电机 & Permanent magnet synchronous motor \\
\hline 37 & 滑模控制 & Sliding mode control \\
\hline 38 & 神经网络 & Neural networks \\
\hline 39 & 遗传算法 & Genetic algorithm \\
\hline 40 & 鲁棒性 & Robustness \\
\hline 41 & 分数阶 & Fractional order \\
\hline 42 & 分数阶混沌系统 & Fractional chaos system \\
\hline 43 & 分数阶系统 & Fractional order system \\
\hline 44 & 参数辨识 & Parameter identification \\
\hline 45 & 同步 & Synchronization \\
\hline 46 & 图像加密 & Image encryption \\
\hline 47 & 混沌 & Chaos \\
\hline 48 & 混沌同步 & Chaos synchronization \\
\hline 49 & 混沌控制 & Chaos control \\
\hline 50 & 混沌系统 & Chaotic system \\
\hline 51 & 滑模 & Sliding mode \\
\hline 52 & 分数阶傅里叶变换 & Fractional Fourier transform \\
\hline 53 & 分数阶微分 & Fractional differential \\
\hline 54 & 分数阶积分 & Fractional integral \\
\hline 55 & 参数估计 & Parameter estimation \\
\hline 56 & 图像去噪 & Image denoising \\
\hline 57 & 图像增强 & Image enhancement \\
\hline 58 & 小波变换 & Wavelet transform \\
\hline 59 & 线性调频信号 & Linear frequency modulation signal \\
\hline 60 & 自适应 & Self-adaptive \\
\hline 61 & 边缘检测 & Edge detection \\
\hline
\end{tabular}




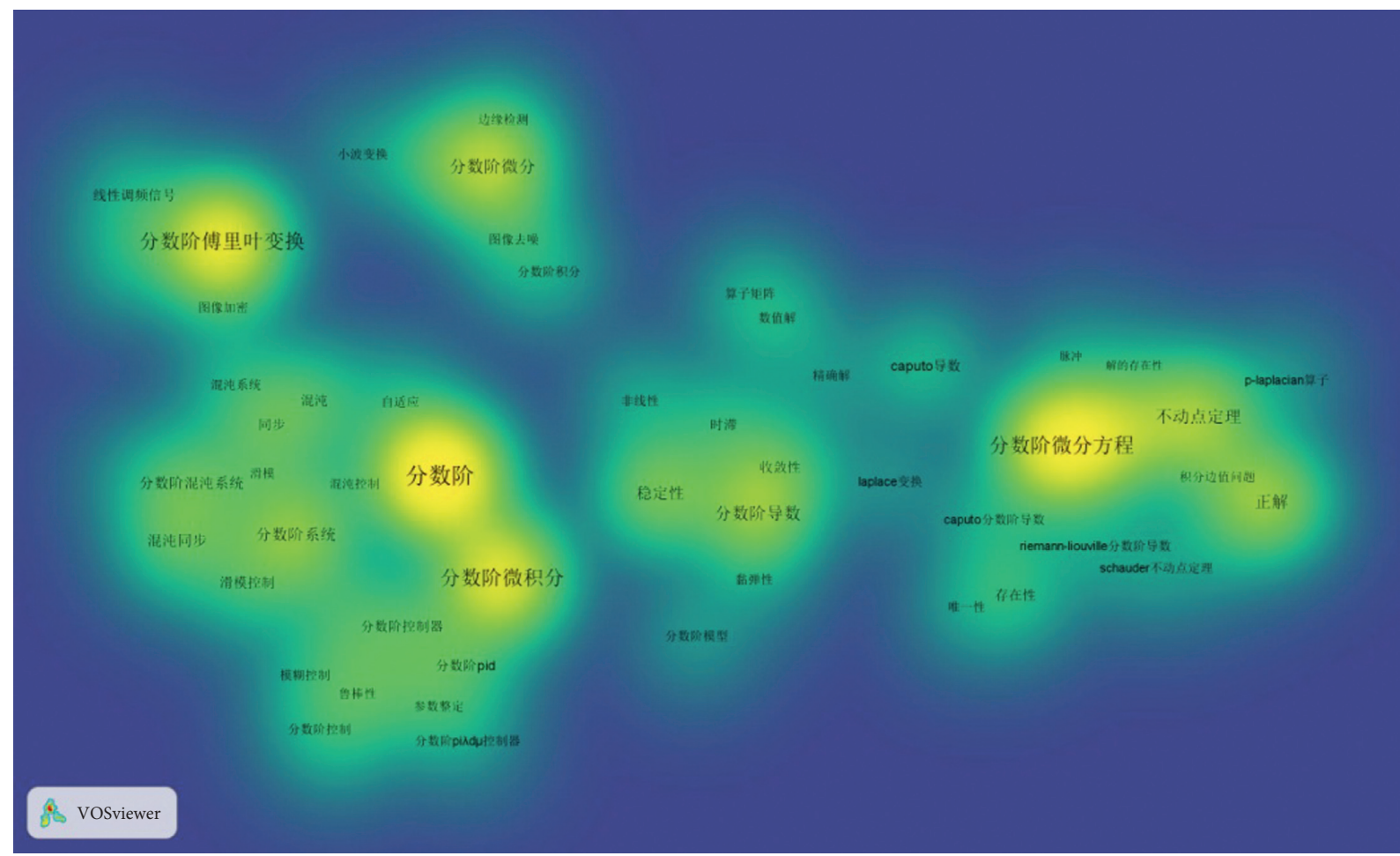

Figure 5: Visualization map of keyword density. Note: the keywords translation in Figure 5 is shown in Table 3.

TABLE 4: Occurrence distribution of the top 20 keywords.

\begin{tabular}{lcc}
\hline No. & Keyword & Occurrence \\
\hline 1 & Fractional order & 342 \\
2 & Fractional differential equation & 250 \\
3 & Fractional Fourier transform & 243 \\
4 & Fractional calculus & 228 \\
5 & Fractional differential & 145 \\
6 & Fixed point theorem & 138 \\
7 & Positive solution & 135 \\
8 & Boundary value problem & 123 \\
9 & Fractional derivative & 119 \\
10 & Fractional order system & 115 \\
11 & Stability & 107 \\
12 & Chaos synchronization & 72 \\
13 & Fractional chaos system & 64 \\
14 & Convergence & 56 \\
15 & Synchronization & 52 \\
16 & Sliding mode control & 52 \\
17 & Chaos & 51 \\
18 & Image enhancement & 51 \\
19 & Existence & 47 \\
20 & Caputo derivative & 45 \\
\hline
\end{tabular}

turbine systems [45], Yu and Huang proposed the fuzzy RBF neural network based fractional order speed control system of permanent magnet synchronous motor [46], and so forth.

Cluster 3 (blue region) represents the research of fractional order in the field of physics. Cluster 3 has 11 keywords, including fractional order, fractional order system, chaos synchronization, fractional chaos system, synchronization, chaos, and sliding mode. Compared with other clusters, the nodes are relatively close in cluster 3 , and the connecting lines between some nodes are relatively thick, such as the connecting lines between fractional order and synchronization, sliding mode, and chaos, as well as the connecting line between chaos synchronization and fractional order system and so forth, which indicates that the research of fractional order in the field of physics is more focused, and the connection of keywords is more closely related. Focusing on the distribution of keyword nodes in cluster 3 , the research hotspots of fractional order in the field of physics are focused on the synchronization and control of fractional order chaotic systems and so forth. Regarding the research of synchronization and control of fractional order chaotic systems, some scholars combined Lyapunov stability theory to explore synchronization of fractional order chaotic systems [47-49], and some others studied the synchronization control of fractional order chaotic system [50,51]. In addition, some scholars analyzed the synchronization and control of fractional order chaotic systems from the perspective of relative subdivision, such as adaptive synchronization or synchronization control of fractional order chaotic systems [52-54], sliding mode synchronization or synchronization control of fractional order chaotic system [55-57], and adaptive sliding mode synchronization or synchronization control of fractional order chaotic system [58-60].

Cluster 4 (yellow region) represents the research of fractional order in the field of computer and information communications. Cluster 4 has 10 keywords: fractional Fourier transform, fractional differential, fractional integral, image enhancement, image denoising, linear frequency modulation (LFM) signal, edge detection, parameter estimation, wavelet transform, and self-adaptive. Compared 
with the first three clusters, the keywords around fractional differential and fractional Fourier transform in cluster 4 are relatively concentrated, but the distance between the keywords around them is far and the connecting lines are relatively less, such as LFM signal and image denoising, which indicates that the research hotspots of fractional order in the field of computer and information communication present the characteristics of partly concentration and general dispersion.

According to the distribution of nodes, there are some keyword node distribution forms clusters, such as the fractional differential, fractional integral, image denoising, image enhancement, edge detection, and self-adaptive, which reflects the application of fractional order in the computer field. Focusing on research field segmentation, we can find that image processing direction is the research hotspot of fractional order in the field of computers. To be specific, regarding the combination of fractional order and image enhancement, there are many research results related to image enhancement algorithm. Many scholars proposed fractional differential image enhancement algorithm, where there were relatively many findings related to adaptive fractional differential image enhancement algorithms, such as adaptive fractional differential MR image enhancement algorithm based on nonlocal means value [61], adaptive fractional order differential image enhancement algorithm based on 3 parameters related to an image texture, which were the local gradient of the image, the information entropy, and the variance [62], and image enhancement algorithm combining adaptive threshold fuzzy set enhancement and fractional differential [63]. Regarding the specific application of fractional differential in image enhancement, it includes medical image [64] and haze traffic image [65]. Regarding the combination of fractional order and image denoising, many scholars focused on the fractional integral theory to explore image denoising methods; for example, they studied image denoising based on fractional integral $[66,67]$ and proposed an improved fractional integration method for laser image denoising [68, 69]. Moreover, some scholars put forward image denoising method by combining fractional integral with wavelet transform [70], and some scholars introduced Gauss curvature into partial differential equation, and the image edge was detected by the image gradient, and they established adaptive image denoising model by combining Gauss curvature and fractional different operator [71]. Through further analysis, it can be found that the research on the application of fractional order in image enhancement focuses more on fractional differentiation, while the research on the application of fractional order in image denoising focuses more on fractional integral.

Combining with Figure 4, it can also be found that the distance between the fractional differential and the image enhancement node is closer, and the distance between the fractional integral and the image denoising node is closer, which indicates that the correlation between the nodes is strong, and the cooccurrence degree is high. Moreover, Huang et al. proposed that the applicable situations of the fractional differential equation, fractional integral equation, and fractional partial differential equation are image enhancement, image denoising, image enhancement, or denoising, respectively [72]. Therefore, it also provides further support and guidance for the above conclusions. According to the node distribution of cluster 4, some keywords form another cluster, such as fractional Fourier transform, LFM signal, and parameter estimation, which represents the application research of fractional order in the field of information and communication. Based on the perspective of research field segmentation, we can find that the direction of LFM signal detection and parameter estimation are the research hotspots of fractional order in the field of information and communication. To be specific, some scholars proposed joint parameter estimation method or signal detection and parameter estimation method of LFM signals based on Fourier transform, such as a novel method for joint parameter estimation of LFM signals in bistatic Multiple-Input Multiple-Output (MIMO) radar system [73], fast adaptive method of the multi-LFM signal detection, and parameter estimation based on fractional Fourier transform [74]. In addition, regarding the detection of the LFM signal or low parameter estimation accuracy of the LFM signal under low signal-to-noise ratio (SNR), some scholars proposed a concise fractional Fourier transform method for LFM signal detection under low SNR [75]. Some scholars aimed at the problem of low parameter estimation accuracy of LFM signal under low SNR, proposed a Rife interpolation short-time fractional Fourier transform(STFRFT-) variable weight least square fitting (VWSF) algorithm [76]. Through further analysis, it can be found that the research findings of fractional order in the direction of LFM signal detection and parameter estimation focus more on the implementation based on the Fourier transform. Combining with the size of the nodes, it can also be found that the Fourier transform has the biggest nodes in this cluster, which means it has the highest frequency. Moreover, the connecting line between some keyword nodes and Fourier transform is relatively thick, such as LFM signal and parameter estimation, which can indicate that the correlation between these keywords is strong and the cooccurrence degree is high. Thus, it can be seen that fractional Fourier transform is an important method for the application of fractional order in information and communication.

Additionally, cluster 4 represents the research of fractional order in the computer and information communication field; the keywords belong to different disciplines, respectively, but they are distributed in the identical cluster because of the similar discipline direction and obvious cross characteristics. Furthermore, it can also be seen from the node distribution in Figure 4 that there are connecting lines among the keyword nodes of fractional order in the computer and information communication field, which further proves the rationality of their distribution in the identical cluster.

Figure 5 shows a visualization map of the keyword density of fractional order research, in which the keyword distribution shows a feature of a gradual change from the cold color region to the warm color region. Among them, the larger the keyword node and the more biased towards the 
warm color series, the higher frequency of its occurrence. On the contrary, the smaller the keyword node and the more biased towards the cold color series, the lower frequency of its occurrence. It can be seen from Figure 5 that some keywords have large nodes and show the distribution characteristics of warm color series, such as fractional order, fractional differential equation, fractional calculus, fractional Fourier transform, fractional differential, fixed point theorem, and positive solution. Especially for the nodes of fractional order, fractional differential equation, fractional calculus, fractional Fourier transform, fractional differential, and so forth, their feature of warm color system is more obvious. Combined with the keyword node distribution in Figure 4, we can see that the keywords are centered on the important nodes such as fractional order, fractional differential equation, fractional calculus, fractional Fourier transform, and fractional differential and radiate to the surrounding keywords of their respective regions. Additionally, combined with the above cluster analysis, it can be seen that these keywords are key points or important methods and tools of fractional order research in the fields of mathematics, control engineering, physics, computer, information communication, and so forth. Therefore, keywords such as fractional order, fractional differential equation, fractional calculus, fractional Fourier transform, and fractional differential are the core points and important support of fractional order research.

In summary, this study analyzed the hotspots of fractional order research from the perspectives of keyword network and density analysis. In addition, it should be noted that some keywords are cross-related with other clusters in the four clusters. For instance, not only is the keyword stability distributed in the research of fractional order in the field of mathematics, but also it involves the fields of physics, control engineering, and so forth. Again, for instance, the keyword chaos not only belongs to the research of fractional order in the field of physics but also is distributed in the fields of mathematics and control engineering. Thus, this also reflects the interdisciplinary characteristics of fractional order research.

4.2. Research Frontiers. Keyword burst not only detects the focus of research on bursts but also realizes the research frontier [77]. Burst detection in CiteSpace is mainly based on the Kleinberg algorithm [78]; burst keyword analysis method shows keywords had rapidly changed in a short period of time or dramatically increased in number and emphasizes the abrupt change of keywords [79]. Therefore, CiteSpace was used to analyze the burst keywords of fractional order research, so as to explore the research frontier of fractional order. The relevant parameters of the software were set as follows: set the time slicing option to be from 2001 to 2020 , set the years per slice option to 2 , set the node types option to keyword, and use pathfinder to trim the keyword network and other options as default settings. By running the software, the cooccurrence distribution of the fractional research keywords was obtained. After a software trial run, it was found that there were repetitions in the expression of keywords about the fractional Fourier transform and LFM signals, so these keywords were merged. On this basis, the minimum duration in the burstness option was set to 3, and finally keywords with the strongest citation bursts of fractional order research were generated, as shown in Figure 6. It should be noted that the above keywords of fractional order and fractional calculus were not merged. In order to keep consistency with the above research, this paper also did not merge the two in this part. At the same time, combining with the analysis results in Figure 5, it can also be found that the burst keywords of fractional order and fractional calculus do not appear in Figure 5 at the same time; thus the fact that these two keywords were not merged has almost no effect on the overall results.

Figure 6 shows the top 26 keywords with the strongest citation bursts. To be specific, "Begin" represents the time when a certain keyword begins to burst, and "End" represents the burst end time for a certain keyword. In addition, the red and blue columns together constitute the time distribution (2001-2020) in the study period, and the red column represents the duration of a burst keyword. It can be seen from Figure 6 that the first burst keyword to appear in the research period is the LFM signal, and this keyword has the longest burst duration (2001-2012). According to the burst strength, the burst strength of fractional Fourier transform is the highest, and its burst value is 33.9667 , which further reveals the importance of fractional Fourier transform in the field of fractional order research. Meanwhile, the burst value of the LFM signal is also relatively high, and its burst value is 15.3201. In addition, combined with the burst strength, it can also be found that the burst strength distribution of other burst keywords is relatively uniform, except for the significant burst strength of fractional Fourier transform and LFM signal, which is consistent with the multidisciplinary distribution characteristics of fractional order research.

Based on the time distribution of burst keywords and the subdivision of fractional order research, the distribution of fractional order burst keywords can be basically divided into the three following phases: The first phase is from 2001 to 2012; the burst keywords in this phase mainly include LFM signal, parameter estimation, information processing technology, fractional calculus, fractional Fourier transform, and edge detection. Through further analysis of burst keywords, it can be found that the research frontier of this phase focuses on the research of fractional order in the field of information communication and computer. Combined with the above clustering analysis, the keywords such as fractional Fourier transform, LFM signal, and parameter estimation form clusters, which indicates the research of fractional order in the field of information and communication, and the burst keywords such as edge detection and wavelet transform also represent the research of fractional order in the field of computer. Meanwhile, projective synchronization of burst keywords also appears in this phase, which mainly involves the application of fractional order in the field of physics, such as the study of projective synchronization in fractional order chaotic system [80, 81]. In addition, compared with the other two phases, the duration of 


\begin{tabular}{|c|c|c|c|c|c|}
\hline Keywords & Year & Strength & Begin & End & $2001-2020$ \\
\hline 线性调频信号 & 2001 & 15.3201 & 2001 & 2012 & \\
\hline 参数估计 & 2001 & 3.3406 & 2003 & 2007 & \\
\hline 信息处理找术 & 2001 & 4.502 & 2003 & 2010 & \\
\hline 分数阶微积分 & 2001 & 5.7086 & 2004 & 2006 & \\
\hline 分数阶傅里叶变搷 & 2001 & 33.9667 & 2005 & 2012 & \\
\hline 边络殓测 & 2001 & 3.6982 & 2006 & 2012 & \\
\hline 投影同步 & 2001 & 4.2511 & 2007 & 2012 & \\
\hline 信号裣测 & 2001 & 3.3981 & 2007 & 2012 & \\
\hline 小波跡撒 & 2001 & 3.2241 & 2011 & 2014 & \\
\hline 初值问题 & 2001 & 4.0334 & 2011 & 2014 & \\
\hline 算子矩阵 & 2001 & 5.7806 & 2012 & 2015 & \\
\hline schauder不动点定理 & 2001 & 4.8559 & 2012 & 2014 & \\
\hline 误䇺估计 & 2001 & 4.095 & 2013 & 2016 & \\
\hline 唯一性 & 2001 & 4.8435 & 2013 & 2016 & \\
\hline 守恒宣 & 2001 & 4.095 & 2013 & 2016 & \\
\hline 不动点定理 & 2001 & 5.4069 & 2013 & 2015 & \\
\hline 奂橦性 & 2001 & 3.8526 & 2014 & 2017 & \\
\hline 积分边值问题 & 2001 & 5.5859 & 2014 & 2017 & \\
\hline 内償控制 & 2001 & 5.4725 & 2015 & 2018 & \\
\hline 分数阶模型 & 2001 & 4.3408 & 2015 & 2017 & \\
\hline 自运应 & 2001 & 4.041 & 2016 & 2020 & \\
\hline 分数阶pid控制 & 2001 & 4.0485 & 2016 & 2018 & \\
\hline $\mathrm{p}$ laplacian算子 & 2001 & 3.8962 & 2016 & 2020 & \\
\hline 精碚解 & 2001 & 5.0128 & 2017 & 2020 & \\
\hline 遗传算法 & 2001 & 4.7115 & 2017 & 2020 & \\
\hline 粈子群算法 & 2001 & 3.906 & 2017 & 2020 & \\
\hline
\end{tabular}

Figure 6: Top 26 keywords with the strongest citation bursts. Note: the keywords translation in Figure 6 is shown in Table 5 .

burst keywords in this phase is longer, such as LFM signal, information processing technology, and fractional Fourier transform, which shows the importance of fractional order in information communication and computer fields. The second phase is from 2012 to 2017; this phase mainly covers burst keywords such as operator matrix, Schauder fixed point theorem, error estimation, uniqueness, fixed point theorem, and integral boundary value problem, which indicates that the research of fractional order in the field of mathematics has become the main frontier direction in this phase. Furthermore, compared with other phases, the number of burst keywords focusing on the identical frontier direction is the biggest in this phase, which further confirms the breadth of fractional order research in the field of mathematics. The third phase is from 2017 to 2020; new burst keywords appeared in 2017, such as exact solution, genetic algorithm, and particle swarm optimization. Among them, the exact solution mainly involves the research of fractional order in the field of mathematics, while genetic algorithm, particle swarm optimization, and so forth mainly involve the research of fractional order in the fields of automotive engineering, control engineering, and so forth. For example, some scholars used genetic algorithm to optimize the parameters of fractional order controller [82, 83] and particle swarm optimization to explore the optimal design of passive fractional order vehicle suspension parameters [84]. Also some scholars proposed a dynamic constriction factor based particle swarm optimization with fractional order velocity (DFFV-PSO) [85]. In addition, at the intersection of the second and third phases, there also appear some burst keywords, such as internal model control, fractional order PID control, and p-Laplacian operator. These burst keywords are mainly distributed around the fractional order in frontier fields such as control engineering and mathematics.

In conclusion, the priorities of the research frontier of fractional order are different in a different phase, which also reveals the law of the dynamic change of the research frontier of fractional order with time evolution. In particular, the burst time of burst keywords such as exact solution, genetic algorithm, and particle swarm 
TABLE 5: Translation of keywords in Figure 6.

\begin{tabular}{lcc}
\hline No. & The keywords & Translation \\
\hline 1 & 线性调频信号 & Linear frequency modulation signal \\
2 & 参数估计 & Parameter estimation \\
3 & 信息处理技术 & Information processing technology \\
4 & 分数阶微积分 & Fractional calculus \\
5 & 分数阶傅里叶变换 & Fractional Fourier transform \\
6 & 边缘检测 & Edge detection \\
7 & 投影同步 & Projective synchronization \\
8 & 信号检测 & Signal detection \\
9 & 小波变换 & Wavelet transform \\
10 & 初值问题 & Initial value problem \\
11 & 算子矩阵 & Operator matrix \\
12 & schauder不动点定理 & Schauder fixed point theorem \\
13 & 误差估计 & Error estimation \\
14 & 唯一性 & Uniqueness \\
15 & 守恒量 & Conserved quantity \\
16 & 不动点定理 & Fixed point theorem \\
17 & 鲁棒性 & Robustness \\
18 & 积分边值问题 & Integral boundary value problem \\
19 & 内模控制 & Internal model control \\
20 & 分数阶模型 & Fractional order model \\
21 & 自适应 & Self-adaptive \\
22 & 分数阶pid控制 & Fractional order PID control \\
23 & p-Laplacian算子 & p-Laplacian operator \\
24 & 精确解 & Exact solution \\
25 & 遗传算法 & Genetic algorithm \\
26 & 粒子群算法 & Particle swarm optimization \\
\hline & &
\end{tabular}

optimization lasted until the end of the research period (2020), so these burst keywords are to a large extent the frontier direction and method of fractional order research now and in the future.

\section{Conclusion}

This paper combined bibliometrics and visualization research methods to conduct a quantitative and visual analysis of the 2,854 Chinese fractional order research literatures collected by CNKI from 2001 to 2020, which explored the current status of China's fractional order research and also revealed the hotspots and frontier areas. The main research conclusions of this paper are as follows:

(1) Research current status aspect: China's fractional order research publications show an overall upward trend, but there are also obvious differences in the distribution of the number of publications in different time series; China's fractional order research publications are relatively evenly distributed among various research institutions, and the attributes of research institutions include comprehensive universities, universities of science and technology, and military academy. The overall intensity of cooperation among Chinese fractional order research authors is not high, but there are also many research groups with a high volume of publications and close cooperation relationships; China's fractional order research disciplines are distributed in a wide range, and the number of publications in the field of mathematics is the biggest, which had the characteristic of the multidisciplinary distribution.

(2) Research hotspot aspect: The research hotspots of fractional order in China are divided into 4 keyword clusters, which include the research of fractional order in the fields of mathematics, control engineering, physics, and computer and information communication. Meanwhile, keywords such as fractional order, fractional order differential equations, fractional calculus, fractional Fourier transform, and fractional differential are the core points and important supports of fractional order research in China.

(3) Research frontier aspect: The focus of China's fractional order research frontier is different at different stages, and it changes dynamically with the evolution of time. Meanwhile, burst keywords such as exact solution, genetic algorithm, and particle swarm optimization are likely to be the frontier directions and methods of China's fractional order research at present and in the future.

\section{Data Availability}

The data collected to support the findings of this study come from CNKI and are available from the corresponding author upon reasonable request.

\section{Conflicts of Interest}

The authors declare that they have no conflicts of interest.

\section{Acknowledgments}

This study was supported by the National Key R\&D Program of China (2018AAA0100804) and the National Natural Science Foundation of China (62032022, 61972375, and 61929104).

\section{References}

[1] L. Wu, S. Liu, and Y. Yang, "Using the fractional order method to generalize strengthening buffer operator and weakening buffer operator," IEEE/CAA Journal of Automatica Sinica, vol. 5, no. 6, pp. 1074-1078, 2018.

[2] M. A. Balootaki, H. Rahmani, H. Moeinkhah, and A. Mohammadzadeh, "On the synchronization and stabilization of fractional-order chaotic systems: recent advances and future perspectives," Physica a-Statistical Mechanics and ITS Applications, vol. 551, Article ID 124203, 2020.

[3] H. Sun, Y. Zhang, D. Baleanu, W. Chen, and Y. Chen, "A new collection of real world applications of fractional calculus in science and engineering," Communications in Nonlinear Science and Numerical Simulation, vol. 64, pp. 213-231, 2018.

[4] A. M. Lopes and J. A. T. Machado, "A review of fractional order entropies,” Entropy, vol. 22, no. 12, Article ID 1374, 2020.

[5] Z. Li, L. Liu, S. Dehghan, Y. Chen, and D. Xue, "A review and evaluation of numerical tools for fractional calculus and fractional order controls," International Journal of Control, vol. 90, no. 6, pp. 1165-1181, 2017. 
[6] M. S. Tavazoei, "Fractional order chaotic systems: history, achievements, applications, and future challenges," European Physical Journal-Special Topics, vol. 229, no. 6-7, pp. 887-904, 2020.

[7] X. Sun, J. Ji, B. Ren, G. Chen, and Q. Zhang, "A novel online identification algorithm of lithium-ion battery parameters and model order based on a fractional order model," IET Renewable Power Generation, vol. 15, 2021.

[8] M. Al-Daloo, A. Soltan, and A. Yakovlev, "Advance interconnect circuit modeling design using fractional-order elements," IEEE Transactions on Computer-Aided Design of Integrated Circuits and Systems, vol. 39, no. 10, pp. 2722-2734, 2020.

[9] S. R. Sahoo and M. C. Ray, "Active control of nonlinear transient vibration of laminated composite beams using triangular SCLD treatment with fractional order derivative viscoelastic model," Journal of Dynamic Systems Measurement and Control-Transactions of the Asme, vol. 141, no. 11, Article ID 111014, 2019.

[10] E. Yumuk, M. Güzelkaya, and İ. Eksin, "Design of an integer order proportional-integral/proportional-integral-derivative controller based on model parameters of a certain class of fractional order systems," Proceedings of the Institution of Mechanical Engineers, Part I: Journal of Systems and Control Engineering, vol. 233, no. 3, pp. 320-334, 2019.

[11] H. Z. Lv, F. Wang, and R. Wang, "Robust active contour model using patch-based signed pressure force and optimized fractional-order edge," IEEE Access, vol. 9, pp. 8771-8785, 2021.

[12] W. Waseem, M. Sulaiman, A. Alhindi, and H. Alhakami, “A soft computing approach based on fractional order DPSO algorithm designed to solve the corneal model for eye surgery," IEEE Access, vol. 8, pp. 61576-61592, 2020.

[13] P. Warrier and P. Shah, "Fractional order control of power electronic converters in industrial drives and renewable energy systems: a review," IEEE Access, vol. 9, pp. 58982-59009, 2021.

[14] A. A. Dastjerdi, B. M. Vinagre, Y. Chen, and S. H. HosseinNia, "Linear fractional order controllers; A survey in the frequency domain," Annual Reviews in Control, vol. 47, pp. 51-70, 2019.

[15] C. Zhu and Y. Zou, "Summary of research on fractional-order control," Control and Decision, vol. 24, no. 2, pp. 161-169, 2009.

[16] Q. Yang, D. Chen, T. Zhao, and Y. Chen, "Fractional calculus in image processing: a review," Fractional Calculus and Applied Analysis, vol. 19, no. 5, pp. 1222-1249, 2016.

[17] Z. Gu, D. Yin, S. Nie et al., "Advances of image edge enhancement based on vortex filtering," Infrared and Laser Engineering, vol. 48, no. 6, pp. 244-257, 2019.

[18] H. Wang, Z. Chen, and R. Gong, "Mapping knowledge domains of industrial structure research in China: 1992-2015," Journal of Discrete Mathematical Sciences \& Cryptography, vol. 20, no. 6-7, pp. 1393-1397, 2017.

[19] N. J. Van Eck and L. Waltman, "Citation-based clustering of publications using CitNetExplorer and VOSviewer," Scientometrics, vol. 111, no. 2, pp. 1053-1070, 2017.

[20] N. J. Van Eck and L. Waltman, "Software survey: VOSviewer, a computer program for bibliometric mapping," Scientometrics, vol. 84, no. 2, pp. 523-538, 2010.

[21] X. Lu, W. Peng, X. Huang, Q. Fu, and Q. Zhang, "Homestead management in China from the "separation of two rights" to the "separation of three rights": visualization and analysis of hot topics and trends by mapping knowledge domains of academic papers in China National Knowledge Infrastructure (CNKI)," Land Use Policy, vol. 97, Article ID 104670, 2020.

[22] B. Wang and Z. Wang, "Analysis of mapping knowledge domains of tennis teaching research in China," Educational Sciences-Theory \& Practice, vol. 18, no. 6, pp. 2979-2988, 2018.

[23] H. Zeng, B. Shao, G. Bian, D. Song, and X. Li, "A survey of research progress and hot front of natural gas load forecasting from technical perspective," IEEE Access, vol. 8, pp. 222824-222840, 2020.

[24] L. Qi, R. Tao, S. Zhou, and Y. Wang, "The detection and parameter estimation for Multi-component LFM signals based on the fractional Fourier transforms," Science in China (Series E), vol. 33, no. 8, pp. 749-759, 2003.

[25] W. Wang and C. Lu, "Visualization analysis of big data research based on Citespace," Soft Computing, vol. 24, no. 11, pp. 8173-8186, 2020.

[26] X. Zhou, T. Li, and X. Ma, "A bibliometric analysis of comparative research on the evolution of international and Chinese green supply chain research hotspots and frontiers," Environmental Science and Pollution Research, vol. 28, no. 6, pp. 6302-6323, 2021.

[27] F. Hu and W. Hu, "Multiple positive solutions for boundary value problems of fractional differential equations with $p$ Laplacian operator," Journal of Northeast Normal University (Natural Science Edition), vol. 52, no. 3, pp. 62-67, 2020.

[28] Z. Peng, Y. Li, and Y. Xue, "Two positive solutions of boundary value problem for a class of coupled system of nonlinear fractional differential equations," Journal of Jilin University (Science Edition), vol. 58, no. 4, pp. 775-781, 2020.

[29] X. Liang and Z. Zhou, "Positive solutions for a class of fractional differential equations with stieltjes integral boundary conditions," Mathematica Applicata, vol. 33, no. 4, pp. 826-835, 2020.

[30] J. Song, "Existence of positive solutions for boundary value problem of nonlinear fractional differential equation," Acta Scientiarum Naturalium Universitatis Nankaiensis, vol. 51, no. 5, pp. 79-84, 2018.

[31] X. Liao, Y. Wei, and C. Feng, "Existence of positive solutions for a class of boundary value problems of fractional differential equations on infinite interval," Journal of Jilin University (Science Edition), vol. 56, no. 6, pp. 1299-1306, 2018.

[32] Y. Nie, J. Hu, and J. Wang, "Douglas-Gunn finite difference scheme for three-dimensional space fractional advection diffusion equation," Journal of Zhengzhou University (Natural Science Edition), vol. 51, no. 1, pp. 44-50, 2019.

[33] J. Yang, Z. Li, and Y. Yan, "A new numerical method for solving riesz space-fractional diffusion equation," Mathematica Numerica Sinica, vol. 41, no. 2, pp. 170-190, 2019.

[34] Q. Xu, J. Huang, and L. Zhou, "ANN-inversion based fractional-order sliding control for the robot," Modular Machine Tool \& Automatic Manufacturing Technique, vol. 12, pp. 4952, 2015.

[35] B. Zhang, F. Gao, and K. Yao, "Neural network and adaptive algorithm-based fractional order sliding mode controller," Control Theory \& Applications, vol. 33, no. 10, pp. 1373-1377, 2016.

[36] X. Wang and Y. Zhang, "Fractional-order sliding mode control based on RBF neural network for AUV path tracking," Journal of Unmanned Undersea Systems, vol. 28, no. 3, pp. 284-290, 2020.

[37] Y. Chen and T. Zhang, "Quadrotor aircraft control based on fractional order PID," Journal of Tianjin Polytechnic University, vol. 38, no. 4, pp. 58-63, 2019. 
[38] Y. Yang, W. Zhang, J. Zhang, C. Li, and K. Li, "Controller design for electromechanical actuator servo system based on fractional-order," Aero Weaponry, no. 6, pp. 50-54, 2018.

[39] L. Guo, G. Dai, G. Li, and S. Pang, "Design and implementation of fractional order $\mathrm{PI}^{\lambda} \mathrm{D}^{\mu}$ controller based on FPGA," Measurement \& Control Technology, vol. 37, no. 1, pp. 64-68, 2018.

[40] J. Yin, R. Wang, Q. Gao, and W. Zhang, "Fractional order PID of AC servo system based on neural network active disturbance rejection control," Electronics Optics \& Control, vol. 26, no. 5, pp. 20-25, 2019.

[41] Y. Yu and P. Xu, "A design of fractional order controller based on internal model control," Packaging Engineering, vol. 39, no. 5, pp. 48-51, 2018.

[42] P. Liu, M. Wang, and M. Yao, "Design of optimized fractional order internal model controller for complex system," Computer Engineering and Applications, vol. 54, no. 21, pp. 224229, 2018

[43] Q. He, J. Niu, and W. Chen, "Application of fractional order terminal sliding mode controller in DTC system," Fire Control \& Command Control, vol. 42, no. 9, pp. 74-78, 2017.

[44] R. Wang, B. Lu, R. Hou et al., "FOPID improved ADRC in AC servo systems," China Mechanical Engineering, vol. 30, no. 16, pp. 1989-1995, 2019.

[45] X. Zhou, X. Wang, T. Hoang, and G. Thu, "Direct-drive permanent magnet synchronous generator wind turbine system based on fractional-order controller," Electric $\mathrm{Ma}$ chines \& Control Application, vol. 44, no. 7, pp. 92-97, 2017.

[46] X. Yu and H. Huang, "Optimization design of fractional-order sliding mode controller based on fuzzy RBF neural network," Modern Electronics Technique, vol. 41, no. 11, pp. 87-90, 2018.

[47] Z. Zhang, Y. Zhang, and Y. Wang, "Synchronization of fractional-order chaotic system with fractional-order controller," Journal of Lanzhou University of Technology, vol. 42, no. 4, pp. 152-158, 2016.

[48] Y. Chen, S. Li, and H. Liu, "Synchronization of fractionalorder chaotic systems based on adaptive fuzzy control," Acta Physica Sinica, vol. 65, no. 17, pp. 258-268, 2016.

[49] X. Yan, T. Shang, and X. Zhao, "Synchronization of uncertain fractional-order chaotic systems based on the fractional-order sliding mode controller," Acta Mathematicae Applicatae Sinica, vol. 41, no. 6, pp. 765-776, 2018.

[50] M. Wu, M. Yu, and Y. Zhang, "Synchronization for fractionalorder chaotic systems with limited gain and uncertain parameters," Journal of University of Jinan (Science and Technology), vol. 31, no. 1, pp. 77-81, 2017.

[51] Y. Bai, Y. Yang, Q. Wei, J. Duan, and M. Fan, "Synchronization research and circuit implementation of fractional chaotic system," Journal of Northwest Normal University (Natural Science), vol. 55, no. 6, pp. 47-52+73, 2019.

[52] D. Li, X. Zhang, Y. Hu, and Y. Yang, "Adaptive synchronization between two fractional-order chaotic systems with uncertain parameters," Journal of Southwest University (Natural Science Edition), vol. 37, no. 11, pp. 69-76, 2015.

[53] F. Lin and Z. Zeng, "Synchronization of uncertain fractionalorder chaotic systems with time delay based on adaptive neural network control," Acta Physica Sinica, vol. 66, no. 9, pp. 40-49, 2017.

[54] K. Shao, Z. Xu, X. Huang, T. Wang, and Y. Zhang, "RBF neural network adaptive synchronization control for fractional-order hyper-chaotic systems," Journal of Yangzhou
University (Natural Science Edition), vol. 23, no. 5, pp. 58-62, 2020.

[55] X. Wang, L. Shi, and B. Mao, "Sliding mode synchronization of fractional-order 4D memristive hyper chaotic systems," Mathematics in Practice and Theory, vol. 50, no. 15, pp. 189-194, 2020.

[56] M. Sun, Y. Hu, and J. Wei, "A novel sliding mode synchronization method of uncertain fractional-order chaotic systems," Journal of University of electronic Science and Technology of China, vol. 46, no. 3, pp. 555-561, 2017.

[57] X. Meng and B. Mao, "Sliding mode synchronization of fractional-order T chaotic systems with logarithmic," Journal of Shandong University (Engineering Science), vol. 50, no. 5, pp. 7-12, 2020.

[58] J. Liu and B. Mao, "Self-adaptive sliding mode synchronization of fractional-order dual-exponential chaotic systems," Mathematics in Practice and Theory, vol. 50, no. 7, pp. 198203, 2020.

[59] C. Cheng, J. Zhu, and D. Wang, "Adaptive synchronization of fractional-order four-wings chaotic systems with uncertainties based on sliding mode control," Journal of Central China Normal University (Natural Sciences), vol. 52, no. 2, pp. 155-159, 2018.

[60] B. Mao and C. Cheng, "Self-adaptive sliding mode control of fractional-order Victor-Carmen chaotic systems," Journal of Shandong University (Engineering Science), vol. 47, no. 4, pp. 31-36, 2017.

[61] N. Yang, Y. Feng, and Y. Wei, "Improved fractional differential algorithm for infant brain MR image enhancement," Journal of Image and Graphics, vol. 21, no. 12, pp. 1696-1706, 2016.

[62] X. Chen and L. Tan, "Medical image enhancement algorithm based on adaptive fractional order differentiation," Application Research of Computers, vol. 34, no. 12, pp. 3895-3898+3903, 2017.

[63] F. Sun, C. Kong, K. Zhang, Y. Jiang, and C. Cong, "DR Image enhancement of femoral head based on adaptive fuzzy set and fractional differential," Computer Applications and Software, vol. 37 , no. 12, pp. 191-196, 2020.

[64] H. Liu, M. Zheng, X. Hou, B. Li, and J. Du, "Enhancement algorithm of fractional differential medical images based on local binary pattern variance," Laser \& Optoelectronics Progress, vol. 56, no. 9, pp. 116-124, 2019.

[65] W. Wang and H. Zhao, "Haze traffic image enhancement based on improved retinex and adaptive fractional differential," Optics and Precision Engineering, vol. 28, no. 8, pp. 1820-1834, 2020.

[66] G. Huang, Y. Pu, Q. Chen, and J. Zhou, "Research on image denoising based on fractional order integral," Systems Engineering and Electronics, vol. 33, no. 4, pp. 925-932, 2011.

[67] X. Qin, M. Chen, W. Jia, J. He, and G. Zheng, "Research on OTC image denoising based on fractional integral algorithm," Optical Technique, vol. 45, no. 1, pp. 102-106, 2019.

[68] J. Cong and B. Zeng, "Laser image denoising based on improved fractional integral," Laser Journal, vol. 37, no. 2, pp. 69-72, 2016.

[69] T. Liu, "Research on laser image denoising based on improved fractional integral," Journal of Inner Mongolia Normal University (Natural Science Edition), vol. 46, no. 2, pp. 216-218+222, 2017.

[70] C. Zhang, M. Chen, F. Wang, N. Gao, and G. Zheng, "Optical coherence tomography image denoising algorithm based on 
wavelet transform and fractional integral," Laser \& Optoelectronics Progress, vol. 56, no. 18, pp. 161-169, 2019.

[71] X. Zhou, M. Zhang, and T. Wu, "Adaptive image denoising based on fractional differential operator and Gauss curvature," Modern Electronics Technique, vol. 42, no. 15, pp. 54-58, 2019.

[72] G. Huang, L. Xu, and Y. Pu, "Summary of research on image processing using fractional calculus," Application Research of Computers, vol. 29, no. 2, pp. 414-420+426, 2012.

[73] L. Li and T. Qiu, "A novel method for joint parameter estimation of LFM signals in bistatic MIMO radar system based on FRFT," Journal of Electronics \& Information Technology, vol. 34 , no. 4 , pp. 878-884, 2012.

[74] W. Shi and X. Xu, "Fast adaptive method of the multi-LFM signal detection and parameter estimation based on fractional fourier transform," Science Technology and Engineering, vol. 12, no. 7, pp. 1517-1521, 2012.

[75] Y. Chen, L. Guo, and Z. Gong, "The concise fractional fourier transform and its application in detection and parameter estimation of the linear frequency-modulated signal," Acta Acustica, vol. 40, no. 6, pp. 761-771, 2015.

[76] W. Cao, Z. Yao, W. Xia, and S. Yan, "Parameter estimation of linear frequency modulation signal based on interpolated short-time fractional fourier transform and variable weight least square fitting," Acta Armamentarii, vol. 41, no. 1, pp. 86-94, 2020.

[77] J. Wu, D. Jia, Z. Wei, and D. Xin, "Development trends and frontiers of ocean big data research based on CiteSpace," Water, vol. 12, no. 6, Article ID 1560, 2020.

[78] L. Meng, K. H. Wen, R. Brewin, and Q. Wu, "Knowledge atlas on the relationship between urban street space and residents' health-a bibliometric analysis based on VOSviewer and CiteSpace," Sustainability, vol. 12, no. 6, Article ID 2384, 2020.

[79] J. Wei, G. Liang, J. Alex, T. Zhang, and C. Ma, "Research progress of energy utilization of agricultural waste in China: bibliometric analysis by Citespace," Sustainability, vol. 12, no. 3, Article ID 812, 2020.

[80] X. Chen Xiang-Rong, C. Li Yong-Xun, and Y. Li, "Nonlinear observer based full-state projective synchronization for a class of fractional-order chaotic system," Acta Physica Sinica, vol. 57, no. 3, pp. 1453-1457, 2008.

[81] X. He Yi-Jie and Y. He, "Projective synchronization of the fractional order unified system," Acta Physica Sinica, vol. 57, no. 3, pp. 1485-1492, 2008.

[82] G. Gao, Q. Xu, and Z. Fang, "Fractional-order $\mathrm{PI}^{\lambda} \mathrm{D}^{\mu}$ control of hybrid mechanism for automobile electro-coating conveying," Machinery Design \& Manufacture, vol. 2, pp. 70-74, 2019.

[83] Y. Chen, M. Yang, H. Xu, and J. Liu, "Vehicle ABS fractional PID control with parameter tuning using genetic algorithm," Manufacturing Automation, vol. 40, no. 1, pp. 24-27+39, 2018.

[84] H. You, Y. Shen, and S. Yang, "Parameters design for passive fractional-order vehicle suspension based on particle swarm optimization," Journal of Vibration and Shock, vol. 36, no. 16, pp. 224-228+254, 2017.

[85] Z. Zhai and S. Su, "A fractional-order particle swarm optimization with dynamic constriction factor," Journal of Chongqing University of Technology (Natural Science), vol. 33, no. 7, pp. 94-101, 2019. 